\title{
АНАЛИЗ МАРКЕТИНГОВОЙ ДЕЯТЕЛЬНОСТИ ОРГАНИЗАЦИИ
}

\author{
(c) 2021 Байрамуков Локман Хусеинович \\ студент-магистр \\ Финансовый университет при Правительстве Российской Федерации, Россия, Москва \\ E-mail: lokman.bayramukov@gmail.com \\ https://orcid.org/0000-0002-7518-8656
}

Предмет / тема: Исследование направлено на изучение маркетинговой деятельности организаций и путей их совершенствования на основе последних методик.

Цели / задачи: Выявление методик совершенствования маркетинговой деятельности на предприятии, а именно разработка системы по совершенствованию маркетинговых стратегий.

Методология: В процессе исследования были использованы научно-исследовательские материалы, учебная литература и статистические данные.

Результаты / выводы: В ходе проведения исследования были раскрыты теоретические аспекты маркетинга и маркетинговой деятельности организации, раскрыта сущность факторов, оказывающих влияние на формирование данных показателей.

Ключевые слова: маркетинг, маркетинговая деятельность, реклама, матрица ВCG, матрица, продукция, услуга, продвижение, исследование рынка, прибыль и рентабельность, пути повышения эффективность организации, тренды, управление бизнесом.

Маркетинговая деятельность - это сфера, которая влияет на деятельность практически каждой организации, на продвижение товаров и услуг. Существует термин «маркетинговый комплекс», описывающий такие процессы в организации как: производство, оценка, размещение и продвижение продукции и услуг на потребительском рынке. Для каждого случая, каждого продукта, а также каждой компании необходимо принятие уникального маркетингового решения, но при этом данное решение должно строиться на базовых принципах маркетинга. Таким образом, маркетинговая программа требует индивидуальной проработки.

Маркетинг не включает в себя только продвижение и рекламу, данные понятия лишь являются лишь составляющими, которые помогают охарактеризовать данный термин. Продвижение и реклама являются аспектами, помогающими охарактеризовать маркетинговую деятельность организации, однако стоит отметить, что существуют другие аспекты и факторы. Внедрение инновационных идей, которые могут помочь бизнесу в создании сильного бренда и налаживания контакта со своими клиентами также являются важными составляющими маркетинговой деятельности.

Для грамотного ведения маркетинговой дея- тельности необходимо эффективное выстраивание коммуникации с клиентом, в ходе которой будут передаваться ценности бренда. Данные ценности будут базой для убеждения в необходимости использования услуг именно данной организации. Для этого необходимо обширный анализ и изучение товаров и услуг, представленных на рынке, а также представленных компаний конкурентов, понимание сильных и слабых сторон. Все это будет в дальнейшем базой для создания эффективной маркетинговой стратегии.

Маркетинг - широкое и многогранное понятие. Слово «маркетинг» (marketing) имеет английское происхождение, в основе которого лежит английское существительное «market», что означает рынок. Данный термин означает дословно «акт покупки и продажи на рынке», а также «торговля» [7, с. 22].

Маркетинговая деятельность предполагает привлечение и удержание внимания людей к определенной продукции и услуге конкретной организации. Организации необходимо изучить рынок, проанализировать полученные данные и таким образом понять интересы потенциального клиента. Маркетинг относится ко всем аспектам бизнеса, включая разработку продукта, методы распространения, продажи и 
рекламу. Таким образом, маркетологи пытаются максимально приблизить продукцию или услуги компании к потребностям клиентов, желающих получить доступ к этим продуктам. Самым важным аспектом для получения компанией прибыли является соответствие продукта клиенту.

Маркетинг в современном его представлении начал образовываться во второй половине XX века. В этот период население начало поглощать информацию не только через печатные средства массовой информации. Начали внедряться в обычную жизнь телевидение, радио, позднее интернет, что обусловило необходимость ведения маркетологами их деятельности на различных платформах. В следствие, маркетологи начали приобретать важное значение для компании, как те, кто помогают точно настроить пути продвижения организацией ее продукции и услуг.

Сущность маркетинга состоит в следующем: необходимо создавать и реализовывать продукцию и услугу, требуемую рынком. Ведь зачастую известна ситуация, при которой компании стараются реализовать то, что уже произведено. Рассмотрим совокупность основных принципов маркетинга.

Филип Котлер дал классическое определение маркетинга: «Маркетинг - это вид человеческой деятельности, направленный на удовлетворение нужд и потребность людей посредством обмена» [5, с. 12].

По словам Эдмунда Джереми Маккарти, теория 4Р маркетинга - это простая формула для определения и работы с основными элементами вашей маркетинговой стратегии.

Теория 4Р маркетинга - это маркетинговая теория, которая основана на 4 основных элементах маркетингового планирования: product, price, promotion, place.

Product (продукт). Наличие продукта является ключевым и, следовательно, корнем всего маркетинга. В этом смысле продуктом будет все, что компания может предложить потребителям, чтобы удовлетворить их потребности. Лучшее, что можно сделать - это выбрать свой продукт или услугу, основываясь как на потребностях и мотивах потребителей, так и на том, как продукт будет полезен для потребителя.

Price (цена). Как мы оцениваем наши продукты и услуги, является чрезвычайно важным решением в рамках маркетинговой стратегии. Цена представляет собой сумму за которую воз- можно будет продать продукцию. Компании необходимо учесть себестоимость продукции, маркетинговые затраты, операционные и коммерческие расходы при установлении цен на продукцию и услуги. Помимо этого, организации необходимо учитывать цены на рынке, то есть цены продукции конкурентов. Таким образом, возможно установить разумную альтернативу для клиентов.

Promotion (продвижение). Это относится ко всем маркетинговым и коммуникационным действиям, которые мы выполняем, чтобы распространить преимущества и характеристики нашего продукта или услуги на рынке.

Имеет место продвижение через рекламные акции, улучшение связей с общественностью, прямой маркетинг, а также спонсорство. С помощью данных направлений можно увеличить в конечном итоге продажи.

Place (место). Место относится к распространению продукта. Ключевые соображения включают в себя, будет ли компания продавать продукт через витрину, через интернет или через оба канала распространения. Целью стратегии распространения является предоставление потенциальным клиентам легкого доступа к продуктам / услугам, а также получение хорошего опыта во течение всего процесса покупки. предоставление хорошего опыта компании на протяжении всего процесса покупки.

Увеличение прибыли является основной целью маркетинга. Это в свою очередь напрямую связано с увеличением стоимости бизнеса. Всего этого можно достигнуть путем выполнения социальной цели компании, а именно удовлетворение индивидуальных потребностей клиентов [3, с. 19]. Если упростить, то можно сказать, что главной целью маркетинга является производить то в чем нуждается потребитель, потенциальный покупатель.

Рассмотрим семь функций маркетинга:

1. Поиск лучших каналов распространения

Распространение - это решение о том, как компания будет поставлять товары или услуги людям, которые хотят их купить. Идея создания продукта - это прекрасно, но, если вы не можете донести этот продукт до клиентов, вы не будете зарабатывать деньги.

2. Финансирование предприятия

Нужны деньги чтобы делать деньги. Как владелец бизнеса, одной из важных функций маркетинга продукта является поиск денег с помо- 
щью инвестиций, займов или вашего личного капитала для финансирования создания и рекламы ваших товаров или услуг.

3. Глубокое исследование рынка

Под исследованием рынка подразумевается сбор информации о ваших потенциальных клиентах. Кто те люди, которым вы хотите продать? Почему они должны покупать у вас, а не у ваших конкурентов? Ответ на эти вопросы требует от вас некоторого наблюдения за тенденциями рынка и конкурирующими продуктами.

4. Установка цен

Установка правильной цены на ваш продукт или услугу может быть сложной задачей. Если вы оцените продукт или услугу слишком высоко, вы можете потерять клиентов, но, если вы установите слишком низкую цену, вы можете лишить себя прибыли.

5. Управление продуктами и услугами

После определения целевого рынка и установления цены своего продукта или услуги, нужно повысить эффективность управления продуктом или услугой. Это подразумевает общение с клиентами, реагирование на их потребности и желания, поддержание актуальности ваших продуктов и услуг.

6. Реклама

Большинство владельцев бизнеса знакомы с идеей продвижения. Реклама ваших продуктов и услуг имеет важное значение для привлечения новых клиентов.

7. Подбор продуктов для клиентов

Хотя мы склонны считать продажи и маркетинг тесно связанными, продажи являются последними в списке из семи функций маркетинга. Продажи появляются только после того, как вы определили потребности своей клиентской базы и сможете ответить нужными продуктами в нужной ценовой категории и в определенные сроки.

Источниками маркетинговой информационной системы являются внутренние данные компании. Это данные, которые создаются и хранятся в компании. Эти данные предоставляют маркетологам информацию о доходах и расходах, которые используются для оценки прибыльности отдельных продуктов.

1. Внутренняя информация компании: информация составляется в форме отчетов или аналитических записок о финансовых результатах, данных о клиентах, рынка сбыта продукции компании, качестве и конкурентоспособности выпускаемой продукции и других конкретных и дополнительных данных. Источником этих данных, как правило, являются записи компаний, бухгалтерские записи, иная доступная информация, однако их недостатком является сомнительная актуальность.

2. Маркетинговая информация: это ценный источник информации, получаемый из различных источников, обычно из внешних каналов, которые могут быть специализированными учреждениями, получающими большие объемы данных для различных целей. С их помощью можно получить обзор конкуренции, отслеживать объемы производства, движения цен, методы продаж, методы продвижения. Такая информация может быть получена с веб-сайтов систем электронных баз данных.

3. Маркетинговое исследование. Наиболее эффективная форма получения необходимой информации - это информация, необходимая для определения проблем маркетинга. Маркетинговое исследование состоит из получения объективных фактов ситуации на рынке, поведения потребителей и потенциальных рисков.

Эффективным инструментом контроллинга маркетинговой деятельности является маркетинговая информационной системы (МИС). Внутренние записи предоставляют информацию о продажах, затратах, запасах, графике производства, реакции посредников и т.д. Ее можно получить из статистических и бухгалтерских записей. Информация из внутренних источников обычно может быть более актуальной и дешевой, чем информация из внешних источников.

МИС должен собирать, систематизировать, обрабатывать и сортировать объем информации, чтобы менеджеры могли легко их найти и быстро получить.

Повседневная информация о различных событиях в маркетинговой среде, которую могут помочь маркетологам и менеджменту разработать маркетинговую стратегию и корректировать маркетинговые планы называется маркетинговой информацией.

Маркетинговые новости могут быть собраны из нескольких источников. Многие из них получены от собственных сотрудников компании - руководителей, менеджеров, инженеров, ученых, покупателей и продавцов [7, с. 92].

Внешние источники маркетинговой информации могут быть общедоступные базы данных, доступ к которым обеспечивается на коммерче- 
ской основе. Данные (информация), собранные в базе данных, доступны 24 часа в сутки на так называемых хост-компьютерах. Соединение с ними строит пользовательские компьютеры для их работы через терминалы, персональные компьютеры и телекоммуникации. Они предоставляют еще более удобные базы данных, хранящиеся на компакт-дисках.

Информация в маркетинге - это информация, ведущая к рациональному управлению производством в связи с быстрым удовлетворением потребностей рынка.

Обычно работают с двумя источниками данных: первичными и вторичными в проектах маркетинговых исследований. Основное различие между ними основано на цели, для которой была собрана информация.

Данные, полученные из первоисточников для исследования, т.е. для какой либо определенной называются первичными данными [6, с. 88].

Информация, которая ранее была собрана компанией для своих собственных нужд, и которая в последующем может быть использована для её новых нужд называется вторичными данными.

Для проведения маркетинговых исследований необходим первичный сбор данных, который невозможен без разработки специального плана, в котором должно быть принято решение относительно метода, методики составления выборки, а также различных способах связей с потребителями.

Маркетинг - это процесс управления всеми основными аспектами предприятия. Он предназначен для формирования наиболее рациональных управленческих решений организации, координации разнообразных сфер и направлений деятельности конкретной компании, а также обеспечения хороших конечных результатов.

Далее необходимо определить механизм воздействия системы факторов и их степень влияния в процессе исследования рынка на объём и структуру спроса на рынке товаров и услуг. Это предполагает построение различных моделей развития рынка и нахождения подходящего для конкретной ситуации и выявление с помощью этого влияние большого количества факторов. Важным определить уровень, на котором стоит выстроить прогноз емкости товарного рынка.

Рассмотрим один из самых распространен- ных методов анализа - SWOT. Благодаря этой матрице можно определить слабые и сильные стороны, а также возможности и угрозы компании. Преимущество метода в том, что он позволяет принимать стратегически важные решения для организации.

С помощью данного метода можно определить возможности компании. А далее определить, что нового компания может привнести на рынок, с помощью каких способы компания сможет привлечь новых клиентов, а также возможно ли и целесообразно ли внедрять новые технологии производства.

Матрица SWOT-анализа заполняется по следующему принципу:

Поле «S» - определяет сильные стороны предприятия, с помощью которых можно определять стратегическое направление деятельности предприятия, а также принимать стратегически важные решения.

Поле «W»- помогает выявить сильные стороны компании, которые используются для уменьшения различных угроз и рисков.

Поле «О» - помогает определить возможности организации, даже при наличии большого количества недостатков.

Поле «Т»- определяет уязвимые места предприятия в условиях угроз.

Также рассматривается методика 4P. Теория 4P маркетинга - это маркетинговая теория, которая основана на четырех основных элементах маркетингового планирования: product (продукт), price (цена), promotion (продвижение), place (место).

Матрица BCG (Boston Consulting Group Matrix) основывается на изучении жизненного цикла товара и эффекта масштаба производства.

Матрица BCG (или матрица доли роста) - это инструмент корпоративного планирования используемый для отображения портфеля брендов фирмы на квадрате вдоль оси относительной доли рынка и оси темпа роста рынка.

Матрица доли роста была основана на логике того, что лидерство на рынке приводит к устойчивой высокой прибыли. В конечном счете, лидер рынка получает самоокупаемое преимущество в стоимости, которое конкурентам трудно воспроизвести. Эти высокие темпы роста указывают на то, какие рынки обладают наибольшим потенциалом рост.

Матрица раскрывает два фактора, которые компании должны учитывать при принятии ре- 
шения о том, куда инвестировать - конкурентоспособность компании и привлекательность рынка - с относительной долей рынка и темпами роста в качестве основных факторов.

Матрица роста доли используется для определения потенциала портфеля бизнес-брендов, для предложения дальнейшей инвестиционной стратегии, с использованием относительной доли рынка и факторов роста отрасли. Данная матрица представляет собой 4 квадрата, каждая из которых является комбинацией относительной доли рынка и роста.

В рамках решения задач маркетингового стратегического анализа, формирования линейки продаж, а также прогнозирования продаж и оказания услуг на рынке используют также матрицу BCG. Эта матрица была предложена одной из крупнейших консалтинговых компаний в мире на основе анализа опыта сотен компаний.

Анализ ассортимента с помощью матрицы McKinsey - General Electric. Матрица «привлекательность отрасли - конкурентоспособность» или матрица McKinsey - это метод портфельного анализа, который используется для разработки стратегий развития ассортимента компании. Матрица состоит из 9 ячеек, которые указывают, должна ли компания инвестировать в продукт, собирать / продавать его или проводить дальнейшее исследование продукта и инвестировать в него, если еще есть какие-то ресурсы. Привле- кательность рынка представлена на оси Y, а конкурентоспособность и компетентность бизнесединицы представлены на оси X [8, с. 61]. Две эти оси делятся на 3 категории (высокая, средняя, низкая) и создают при этом девять ячеек. Бизнес-единица вводится в матрицу с помощью кружков, размеры которых представляют собой объем оборота.

Для правильного построения матрицы необходимо выполнение 5 ключевых последовательных задач: выбор критериев; оценка веса критериев; оценка каждого сегмента; выбор целевых сегментов; прогноз потенциала сегментов.

Главная особенность модели Мак-Кинзи это использование весовых коэффициентов при построении модели, а также учет трендов развития отрасли. Эта матрица является вариантом анализа портфеля Boston Consulting Group (BCG).

Существует большое количество методов анализа, однако при этом каждая конкретная компания должна исходить из собственных нужд и стараться интегрировать данные методики исходя из собственного опыта. Для повышения спроса необходимо проводить эффективные рекламные кампании, тщательно подбирая рекламные инструменты, более результативные и менее затратные. Таким образом, маркетинг повышает эффективность и прибыльность, а также является неотъемлемой частью политики предприятия.

\section{Библиографический список}

1. Аверина О.И. Комплексный экономический анализ хозяйственной деятельности: учебник / О.И. Аверина.М.: КноРус, 2017.- 432 с.

2. Аверчев И.К. Как оценить эффективность работы компании / И.К.Аверчев // Финансовый директор.2018. - № 3. - С. 15-21.

3. Алексеева А.И. Комплексный экономический анализ хозяйственной деятельности: учебное пособие / А. И. Алексеева, Ю. В. Васильев, А. В. Малеева, Л. И. Ушвицкий.- М.: КноРус, 2019. - 706 с.

4. Анисимова Н.А. Планирование и анализ маркетинга: учебное пособие / Н.А.Анисимова, Т. И. Смотрова М.: Русайнс, 2020.- 180 с.

5. Арутюнова Д. В. Стратегический менеджмент: Учебное пособие/ Д. В.Арутюнова.- Таганрог: Изд-во ТТИ ЮФУ, 2019.-452c.

6. Григорьев, М.Н. Маркетинг: учебник для прикладного бакалавриата / М.Н. Григорьев.- Москва: Издательство Юрайт, 2019. - 559 с.

7. Карпова С. В. Маркетинг: теория и практика: учебное пособие для бакалавров / С. В. Карпова.— Москва: Изд. Юрайт, 2019.- 408 с.

8. Кондратенко Н.М. Маркетинг: учебник и практикум для прикладного бакалавриата / Под общ. ред. Н. М. Кондратенко.- М.: Изд. Юрайт, 2018. - 408 с. 